\title{
Simulation model for predicting the concentration of reactant parameters in water distribution systems
}

\author{
Modèle de simulation pour prédire la concentration des paramètres réactifs \\ dans les systèmes de distribution d'eau
}

\author{
par Y. Kadar \\ Mekorot Water Company, Ltd., Tel-Aviv (Israel) \\ M. Rebhun \\ Civil Engineering Faculty, Technion-Haifa (Israel)
}

\author{
A. Adin \\ Graduate School of Applied Science, The Hebrew University of Jerusalem
}

\begin{abstract}
Même si la qualité de l'eau est acceptable quand elle quitte la source ou l'usine de traitement, elle peut se détériorer dans le réseau de distribution. La concentration en constituants non conservatifs ou réactifs, tels que les chlorures, les nitrates, THM etc. est affectée à la fois par les mélanges aux næuds du réseau et par les processus chimiques et biologiques lors de l'écoulement dans les tuyaux. Dans les réseaux complexes, la simulation de la qualité des constituants non conservatifs nécessite une capacité mémoire interne et un temps de calcul considérables, en raison du grand nombre d'équations non linéaires [1].

Cet article s'appuie sur une approche état stable pour modéliser les réseaux de tuyauteries et de réacteurs, prenant en compte les réactions de premier et de second ordres.

Le modèle qui a été développé dans ce travail permet la simulation de grands systèmes de distribution d'eau avec un grand nombre de canalisations et de nauds. Ainsi, on peut mieux contrôler le transport des paramètres de qualité et surveiller le mouvement de contamination accidentelle à l'intérieur des systèmes de distribution.
\end{abstract}

\section{I $\square$ INTRODUCTION}

Increasing occurrences of water quality deterioration in drinking water distribution systems have been documented in Israel and throughout the USA and Europe.

Until recently most of the interest in drinking water quality has been focused on water leaving the sources or the treatment plant. Since the finished water may undergo substantial changes before it reaches the user, there is a growing interest in the developing and implementation of quality models for distribution systems.

Quality parameters in drinking water are generally classified by two major categories: (1) conservative parameters (CP), such as chloride, magnesium etc. and (2) non-conservative or reactant parameters (NCP), such as chlorine, trihalomethanes, nitrates, carbonates etc.

The concentration of conservative parameters in distribution systems is affected by the mixing of water from different sources at the nodes of the network.

The concentration of the non-conservative parameters is affected by the mixing of water from different sources and by both microbiological deterioration and chemical reactions through the distribution system.
Most of the NCP simulation models are limited to the prediction of chlorine residual decay in steady state condition of the distribution systems $[2,3,4,5]$.

Most of the known quality models are based on hydraulic modeling of the network. The assumptions made in order to simplify the models were as follows : one dimensional plugflow, first order reaction rate, no diffusion, perfect mixing at the nodes and conservation of fluxes.

The main problems in these studies were the sensitivity of the quality models to hydraulic modeling assumptions and results. The unsteady flow models of the $\mathrm{CP}$ and the steady flow model of the NCP require remarkable capacity of internal computer memory and run time for large systems, due to a large number of non-linear continuity equations.

This paper suggests new approach to the simulation of tracking the dissolved NCP 's in the bulk stream of water distribution system, assuming first order reactions.

The new approach, the concept of the model and preliminary results are described. Further results and the application of the model to complex water supply systems, as well as model extension to more complicated kinetic, such as second and zero order reactions, will be described in the future. 


\section{Q QUALITY SIMULATION MODEL}

\subsection{Detailed quality model (DQM)}

Hydraulic simulation of water network is based on simultaneous solution of continuity equations at all nodes, i.e.. inflow into the node needs to be equal to the outflow (Eq. 1) and on energy balance for all loops, where for each pipe $i j$, belonging to a loop, $h_{i j}$ the frictional loss in the pipe (Eq. 2).

$$
\sum_{j=1}^{N} q_{i j}=0 \quad \forall \text { nodes } i
$$

where : $\mathrm{N}-$ no. of nodes, $q i j-$ flow from node $\mathrm{i}$ to node $j$.

$$
\sum h_{i j}=0
$$

The hydraulic solution of the network enables the determination of the flows and velocity in all the pipes and the water pressure in each of the nodes.

The behavior of the contaminants in the network is determined through the solution of convection in the pipes and mixing at nodes. Mass balance is included in the continuity equations (Eq. 3) and the concentration at the bulk stream is calculated by Eq. 4 , assuming plug flow and first order reaction rate.

$$
\sum_{j=1}^{N} q_{i j} c_{i j}^{p}=0
$$

where : $C_{i j}-\mathrm{NCP}$ concentration in pipe $i j$ and $p-$ quality parameter.

By calculating the mean residence time $t$ in each pipe of the network the DQM enables the prediction of the NCP's concentration, assuming first order decay rate (Eq. 4).

$$
C_{t}=C_{0} \mathrm{e}^{-k t}
$$

where : $C_{0}-$ initial concentration and $k-$ decay rate coefficient.
The quality models generally "ride " on the hydraulic solution. The flow and residence time series of the hydraulic solution provides the data for the simultaneous solution of the above equations.

\subsection{Reactor network model (RNM)}

\subsection{Segregeted flow model}

Completely segregated flow reactor can be modelled [6] by several piston flow reactors in parallel, or as a single piston flow reactor with side exits (fig. l). Each stream travels through the reactor in a discrete form, and behaves as a small batch reactor. They have different exit concentrations, depending on the particular value for $t$. Mixing between the discrete streams takes place only at the reactor exit, where they merge to form the outlet stream. The mean concentration over all streams at the reactor outlet is the expected concentration of all the streams over the residence time distribution (RTD) density function, $f(t)$.

$$
\left\langle\tilde{C_{A e}}\right\rangle=\int_{0}^{\infty}\left\{C_{A i}(t)\right\}_{b n} f(t) d t
$$

For better illustration of the approach and methodology, let assume a water network composed of n-th parallel pipes (fig. 2 ). This network can be modeled as $n$ piston (plug) flow reactors in parallel, assuming turbulent flow in each of the pipe. Each reactor with a specific residence time, depending on the flow velocity and the length of reactor.

It is suggested in the present article that this system of parallel reactors can be modeled to a single mixed reactor with an equal distribution of residence time.

The RTD density function, $f(t)$, in a single mixed reactor, describes the fraction ratio per unit time $(\mathrm{d} t)$ of the discrete fragments which spend in the reactor a time between $t$ and $t+\mathrm{d} t$.

Considering the completely segregated flow reactor, described in figure 1, the most suitable RTD density function for water pipes network is considered to be the Uniform Distribution.

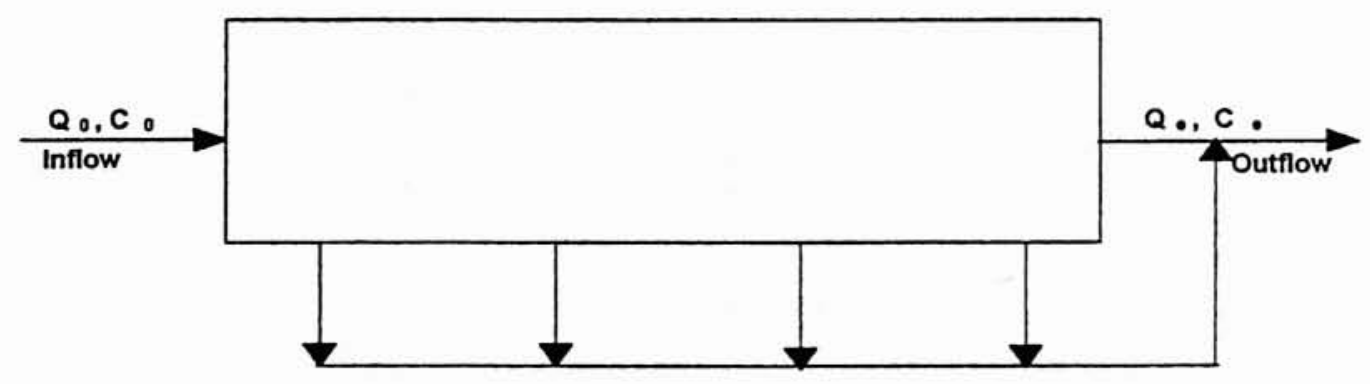

(b)

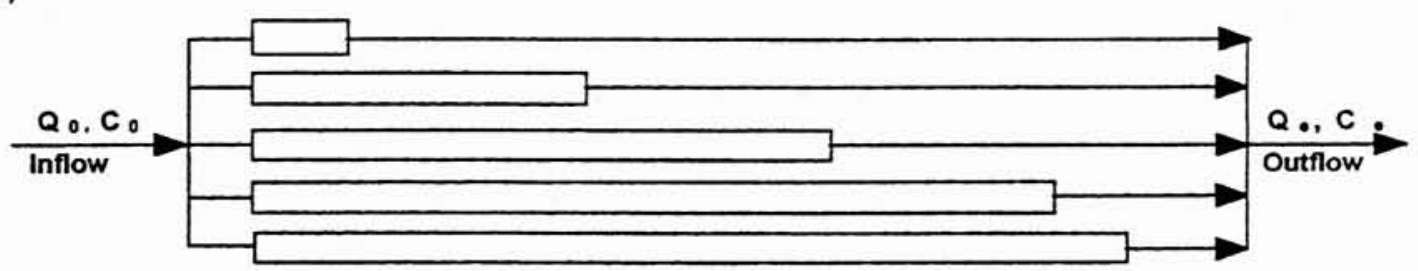

\section{Segregated flow model.}




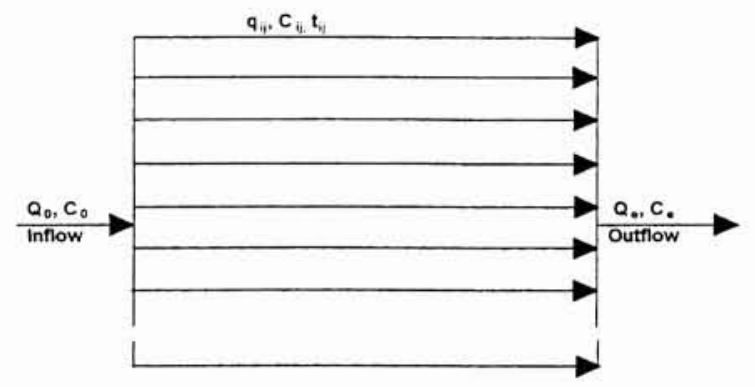

2. Closed water system with parallel pipes.

Mathematically this function is defined as follows,

$$
f(t)=\left\{\begin{array}{cc}
\frac{1}{b \pm a} & a \leq t \leq b \\
0 & t \notin(a, b)
\end{array}\right.
$$

The mean residence time $\tau$ is defined by Eq. 7 .

$$
\tau=\int_{a}^{b} \frac{1}{b \pm a} t d t=\frac{b+a}{2}
$$

\subsubsection{First order reactions}

First order reaction rate is always suggested, while tracking the concentration of the NCP's in water distribution system. A specific example is the decay kinetic of chlorine.

The kinetic equation for $\mathrm{n}$-th order batch reaction is described by Eq. 8 .

$$
\Re_{A}=k C_{A}^{n}
$$

where: $, \Re_{A}= \pm \frac{d C_{A}}{d t}, k \pm$ kinetic coefficient,

$\mathrm{CA}$ - concentration of quality parameter A

For first order reactions $(n=1)$ Eq. 8 becomes to Eq. 9 :

$$
\Re_{A}=k C_{A}
$$

In a plug flow reactor the composition of fluid varies from position to position along a flow path, consequently, the material balance for a reaction component must be made for a differential element of volume $d V$. Each component in the differential volume undergoes batch processes.

Steady-State material balance over the plug flow reactor $i$ with a mean residence time $\tau_{i}$, gives the concentration of quality parameter $A$, as described by Eq. 10 .

$$
C_{A e}=C_{A 0} \mathrm{e}^{-\tau_{i}}
$$

By mathematical integration over the interval of the residence time, the mean concentration of quality parameter $A$, in the exit stream of the system is presented by Eq. 11 .

$$
\left\langle\tilde{C}_{A}\right\rangle=C_{A 0} e^{ \pm \tau \tau} \operatorname{Sinh}(\hat{a} k) \frac{1}{\hat{a} k}
$$

The residual fraction in the exit stream is given by :

$$
\left\langle\frac{\tilde{C}_{A}}{C_{A 0}}\right\rangle=e^{ \pm k \tau} \operatorname{Sinh}(\hat{a} k) \frac{1}{\hat{a} k}
$$

Let define : $M=k \tau$ as the first order primary reaction group and $M^{\prime}=k \hat{a}$ as the first order secondary reaction group. Eq. 12 becomes :

$$
\left\langle\frac{\widetilde{C_{A C}}}{\overline{C_{A 0}}}\right\rangle=e^{ \pm M} \operatorname{Sinh}(M) \frac{1}{M}
$$

Eq. 13 is composed of two main multiples :

(i) $\mathrm{e}^{-M}$ which defines the conversion of quality parameter in an ideal plug reactor with mean residence time of $\tau$.

(ii) $\operatorname{Sin} h\left(M^{\prime}\right) \frac{1}{M}$ which defines the deviation of the system conversion computed by a single ideal reactor with mean residence time $\tau$, Let us define it by the symbol $D e$.

The value of $D e$ as a function of $M^{\prime}(\hat{a} k)$ is described in figure 3 .

Two values of the kinetic coefficient were recognized :

$$
k=0.023 \frac{1}{\min } \text { and } k=0.0115 \frac{1}{\mathrm{~min}} \text { which are compatible }
$$

with the constituent's $t_{1 / 2}$ of 30 and $60 \mathrm{~min}$, respectively. The values of the residence time interval $\hat{a}$ were taken between 10 and $90 \mathrm{~min}$.

From figure 3 it can be seen that the factor De depends on the values of $M^{\prime} . M^{\prime}$ is composed of two parameters : $\hat{a}$ which defines the interval of the residence time distribution function and the kinetic coefficient $k$. For low values of $M^{\prime}$, which means slow reaction and/or low interval values of residence times, the RNM can be presented by an ideal plug flow reactor with an average residence time of $\tau$ for higher values of $M^{\prime}$, which means faster reactions and/or higher values of $\hat{a}$, the ideal plug reactor cannot simulate the RNM and a correction parameter $-D e-$ should be added.

These results are in accordance with the chemical reactors engineering $\{7,8,9]$ which claims that increasing the values of reaction rate, results in increasing the difference in conversion between mixed reactor to plug flow reactor.

Further calculations in a typical water supply system (unpublished), show significant match of the NCP's residual concentration in both the DQM and the equivalent RNM.

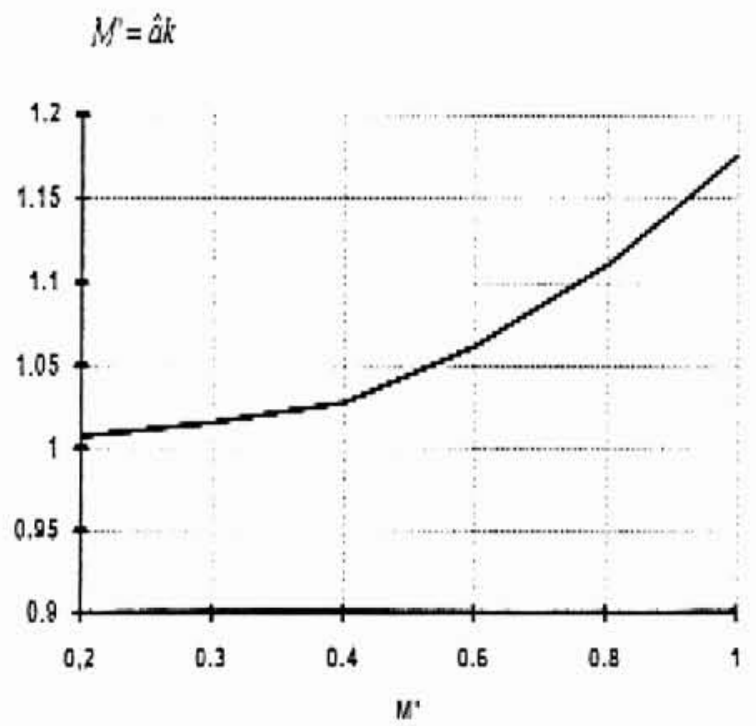

3. $D e$ as a function of $M^{\prime}$ for the first-order reaction. 


\section{au : ressources, aménagements, environnement}

\section{REFERENCES}

[1] Shamir U., Howard D.D.C. (1991), - Topics in modeling water quality in distribution systems. Proc., AWWARF/EPA Conf. on Water Quality Modeling in Distribution Systems, Cincinnati, Ohio, 183-191.

[2] Rossman L.A., Clark R.M. and Grayman W.M. (1994), - Modeling chlorine residuals in drinking water distribution systems. J. Envir. Eng., ASCE, 120, 4, 803-820.

[3] Biswas P. \& ClaRK R.M. (1993). - Model for chlorine contamination decay in drinking water distribution pipes. Water Res., 27, 12, 1715-1724.

[4] Wable O., Dumoutier N. and Duquet J.P. (1991). Modeling chlorine concentrations in a network and applications to Paris distribution network. Proc. AWWARF/EPA
Conf. on Water Quality Modeling in Distribution Systems, Cincinnati, Ohio, 77-87.

[5] Boulos P.F., Altman T., Jarrige P.A. and Collevati F. (1994). - An event-driven method for modelling contaminant propagation in water networks. J. Appl. Math. Modelling, 18, 84-92.

[6] Zwietering T.N. (1959), - The degree of mixing in continuous flow systems. Chem. Eng. Sci., 11, 1, 1-15.

[7] WEN C.Y. \& FAN L.T. (1985). - Models for flow systems and chemical reactors. Chem. Process. Eng.. 3, 423-451.

[8] Nauman E.B. \& Buffham B.A. (1983) - Mixing in continuous flow systems. John Wiley \& Sons, Inc., N.Y.

[9] Levenspiel O. (1962). - Chemical reaction engineering An introduction to the design of chemical reactors. John Willy and Sons, Inc., N.Y. 